REF - ISSN 1808-0804 Vol. VI (2), 62 - 71, 2009

\title{
CONCEPÇÕES E FUNÇÕES AVALIATIVAS EM ANATOMIA HUMANA
}

\section{Concepts and Evaluative Functions in Human Anatomy}

\section{Fabiana Ribeiro da Mata'; João Roberto da Mata ${ }^{1}$; Márcio Christian Rodrigues Souza²; Sara Dayane Santos ${ }^{3}$.}

\author{
${ }^{1}$ Universidade Federal de Goiás, Campus Samambaia \\ (Campus II) - ICB-III - Departamento de Morfologia, \\ CEP: 74001-970 - Caixa Postal: 131 - Goiânia - Goiás.
}

${ }^{2}$ Biomédico, Especialista em Docência Universitária pela Universidade Católica de Goiás.

${ }^{3}$ Acadêmica em Odontologia - UniEVANGÉLICA - Centro Universitário de Anápolis Goiás.

Autor para correspondência: jrdamata@pop.com.br

\section{Recebido em 08/04/2008 - Aceito em 06/03/2009}

RESUMO: Este estudo teve como propósito identificar e analisar as concepções e funções avaliativas na visão dos professores e alunos, da disciplina de anatomia humana, do primeiro ano do curso de Odontologia da Universidade Federal de Goiás. Foi realizada a revisão da literatura sobre as concepções e práticas avaliativas no processo ensinoaprendizagem, seguido do levantamento de dados sobre o ponto de vista de professores e alunos, no intuito de compreender melhor as dificuldades que professores e alunos enfrentam durante o processo avaliativo na disciplina de anatomia humana. Constatou-se a forte presença da concepção tradicional de avaliação, onde a prova é o principal instrumento avaliativo, e tem como finalidade medir conhecimentos e determinar a aprovação. Foi constatada a necessidade de repensar alguns aspectos da avaliação, para que ela possa efetivamente estar a serviço da aprendizagem na disciplina de anatomia humana e contribuir para a formação e qualificação dos futuros cirurgiões dentistas.

PALAVRAS-CHAVE: Educação superior, anatomia, odontologia. 


\section{ABSTRACT}

This study had as an objective to identify and analyse the concepts and evaluative functions in the view of professors and students of the human anatomy course of the first year Dentistry class of the Federal University of Goias. A review of the literature was performed regarding the concepts and evaluation practices in the teaching and learning process, followed by obtaining data on the point of view of professors and students, with the intent to better understanding the challenges faced by professors and students during the evaluation process in the discipline of human anatomy. It was observed that there is a strong presence of a traditional evaluative concept, whereby the exam is still the principal evaluation instrument, and has as a final objective to measure knowledge and determine a passing grade. It was observed also that there is a need for rethinking some aspects of the evaluation process, so that learning in the discipline of human anatomy can be effectively served, as well as to best contribute to the formation and qualification of future dentistry surgeons.

Keywords: Education Higher, anatomy, dentistry. 


\section{INTRODUÇÃO}

Avaliar tornou-se, na sociedade atual, uma ação constante e indispensável ao longo da vida pessoal e profissional dos indivíduos. A avaliação fornece importantes informações para o professor, a respeito de como e se está ocorrendo de fato $o$ ato de ensinar e aprender. Avaliar é fazer juízo. O conceito de avaliação é formulado a partir das determinações e condutas de atribuir um valor ou qualidade a alguma coisa, ato ou curso de ação (LUCKESI, 1991; 1995; ALMEIDA, 1997; LUCKESI, 1998).

A avaliação, como um caminho para a transformação e emancipação possíveis, qualifica e dignifica o ensinar e o aprender (ZOCCHE, 2007), porém dependendo da forma como é conduzida, esta pode ser um instrumento autoritário, punitivo e estigmatizante, (MOREIRA, 2006). Assim a avaliação consiste em um valoroso instrumento no processo de ensinoaprendizagem, no momento em que ela passa a ser entendida e utilizada não como um obstáculo, mas sim como uma importante aliada do professor e aluno rumo à construção do conhecimento. (LUCKESI, 2000). Nesse sentido a avaliação deve ser um recurso pedagógico útil e necessário para auxiliar cada educador e cada educando na busca e na construção de si mesmo e do seu melhor modo de ser na vida. Portando a avaliação deve ser amorosa, inclusiva, dinâmica e construtiva e não se limita a medir, mas sim a entender, analisar, rever, refletir, pois educação e avaliação não podem ser vistas como processos tecnicista, desligados de valores humanos (CHAVES, 2001).

Os aspectos que envolvem a avaliação devem primar pela abordagem crítica e reflexiva, como forma de acompanhar o aprendizado do aluno, pois avaliar não se restringe apenas a mensurar e controlar o ensino, mas acompanhar, interpretar e comunicar (HOFFMANN, 1991; CUNHA, 1998; WACHOWICS, 2002; METZNER, 2002). De fato, a avaliação deve garantir ao aluno a compreensão, assimilação e construção de conhecimentos que lhe possibilitem exercer a sua cidadania (CHAVES, 2001).

A matriz curricular dos cursos da área da saúde apresenta a disciplina de anatomia humana como pré-requisito para a compreensão e aprendizagem das demais disciplinas específicas de cada curso. A maioria dos alunos que cursam a disciplina de anatomia humana encontra dificuldades em compreender os conhecimentos pertinentes à disciplina, pois o docente trabalha durante as aulas com um grande número de informações visto que a disciplina se constitui de aulas teóricas e práticas havendo a necessidade da presença dos discentes no laboratório para estudo em horário extra-aula.

É notório que o exercer a ação de ensinar também está em construção o efetivo desenvolvimento da docência (ROLDÃO, 2007), e a pesquisa da 
qualidade do desempenho docente com base na informação dos alunos é um dos parâmetros aceitáveis (BOCLIN, 2004). Entendendo a avaliação como um instrumento capaz de facilitar e favorecer a aprendizagem, ela pode ser utilizada pelos docentes de modo a amenizar as dificuldades dos discentes em relação à anatomia humana, refletindo positivamente na formação de cirurgiões dentistas.

O presente trabalho objetivou identificar e analisar as concepções e funções avaliativas na visão dos professores e alunos, da disciplina de anatomia humana, do primeiro ano do curso de Odontologia da Universidade Federal de Goiás (UFG). Trata-se de um tema relevante, pois como levantado pela literatura, isto permite compreender melhor o verdadeiro papel da avaliação no processo ensino-aprendizagem, na disciplina de anatomia humana no curso de Odontologia.

\section{METODOLOGIA}

Este estudo foi realizado no Departamento de Morfologia, do Instituto de Ciências Biológicas, da Universidade Federal de Goiás no ano de 2007. O universo explorado consistiu de professores e alunos da disciplina de anatomia humana, ministrada para o curso de Odontologia. Utilizou-se a metodologia descritivo-exploratória através da abordagem qualitativa, para buscar a compreensão profunda a acerca do verdadeiro papel da avaliação no processo ensino-aprendizagem. Foi utilizado um questionário contendo cinco questões discursivas, abordando os aspectos da concepção e função da avaliação no aprendizado. Foram distribuídos 62 questionários para professores e alunos em ambiente calmo e fora do período de avaliação formal da disciplina. Através das respostas aos questionários, foi feito a coleta dos dados segundo a visão dos professores e alunos objetos da pesquisa. Os dados foram tabelados e discutidos pela confrontação com a literatura pertinente.

\section{RESULTADOS E DISCUSSÃO}

O conceito de avaliação para a maioria dos alunos $(81,9 \%)$ consiste em verificar o aprendizado, medir/ testar o grau de conhecimento e avaliar o conhecimento (Tabela 1).

Tabela 1 - Conceito de avaliação apontado pelos alunos da disciplina de anatomia humana do primeiro ano do curso de odontologia da Universidade Federal de Goiás.

\begin{tabular}{|c|l|}
\hline $\begin{array}{c}\text { \% de } \\
\text { alunos }\end{array}$ & \multicolumn{1}{|c|}{ Conceito de avaliação } \\
\hline 81,9 & $\begin{array}{l}\text { Verificar o aprendizado / medir/testar o grau de conhecimento / avaliar o } \\
\text { conhecimento }\end{array}$ \\
\hline
\end{tabular}




\begin{tabular}{|l|l|}
\hline 5,4 & Provar/cobrar o aprendizado \\
\hline 7,2 & Forçar a aprender estudar / Identificar os alunos preparados \\
\hline 3,6 & Analisar a capacidade do professor de ensinar \\
\hline 1,8 & Promover o aprendizado \\
\hline
\end{tabular}

Percebe-se que as diversas concepções de avaliação dos alunos, evidenciam principalmente a redução da avaliação a simples constatação/verificação e quantificação do nível de conhecimentos adquiridos. Isso é o reflexo da forte influência da pedagogia tradicional, cujo objetivo é enfocar o grau de conhecimentos adquiridos e o domínio dos conteúdos, a qual norteou, por muito tempo, os rumos e os objetivos da educação brasileira. Os alunos também apontam a avaliação como forma de provar/cobrar o aprendizado (5,4\%), forçar a aprender/estudar e identificar aqueles considerados "preparados" $(7,2 \%)$. Nestes casos, há então uma inversão de prioridades: a avaliação está associada primeiramente à necessidade de cobrar, obrigar, provar, selecionar e classificar os conteúdos, enquanto o processo de construção do conhecimento é colocado em segundo plano.

A avaliação não se limita a apenas uma verificação obrigatória dos conhecimentos, mas refere-se a um conceito abrangente, na medida em que fornece informações sobre a relação professor-aluno, revelando como e se realmente está ocorrendo o ensino e a aprendizagem. Portanto, assemelha-se a um mapa apontando as direções e o melhor caminho a seguir no intuito de se chegar ao objetivo desejado, ou seja, a real aprendizagem. Assim para que a avaliação contribua com a aprendizagem torna-se necessário que ela inicialmente verifique, mas que, num segundo momento, oriente como sanar as deficiências e atingir os objetivos conduzindo efetivamente a construção do conhecimento (DEPRESBITERIS, 1989; LUCKESI, 1998).

\section{A função formativa da avaliação} alcança o seu pleno sentido, tanto no que diz respeito ao âmbito didático desenvolvendo o processo de ensino e de aprendizagem nas melhores condições possíveis quanto no que se refere ao âmbito psico-pedagógico adaptando as atividades às características, necessidades e possibilidades da aprendizagem dos alunos e ainda no que se refere ao âmbito social moldando atitudes e decisões, que vão repercutir na vida do aluno fora da universidade. Assim a avaliação vinculada ao processo de ensino-aprendizagem, deixa de priorizar a classificação, discriminação e a mera verificação de medidas e passa a acompanhar, intervir, detectar as diferenças e promover o desenvolvimento pessoal e profissional dos indivíduos (CHAVES, 2001).

Os professores por sua vez, vêem à avaliação como maneira de observar o nível de aprendizado alcançado pelos 
alunos e verificar a eficácia da metodologia adotada. Evidencia-se então uma concepção "mista" ou de "transição" de avaliação incluindo características da pedagogia tradicional bem como da pedagogia renovada, onde a avaliação avalia não apenas o aluno, mas também os recursos didático-pedagógicos adotados pelo professor.

Há também, entre os alunos, referência à concepção mais progressista da avaliação, apontando-a como forma de obter dados sobre a didática e a metodologia adotada pelo professor. Embora represente uma pequena parcela do total de alunos $(3,6 \%)$ já se constitui o início de discussões sobre o que verdadeiramente venha a ser a avaliação.

Assim como na Odontologia, estudos demonstram que também nos cursos de Enfermagem, Letras e
Matemática há uma preocupação, ainda que tímida, com as questões didáticopedagógicas. (CHAVES, 2001) Esse fato se constitui em um avanço nas discussões sobre a educação e a avaliação no ensino superior, visto que a maioria dos professores universitários, exceção à área da educação, não considera importantes tais reflexões (LUCKESI, 1996).

O entendimento sobre as concepções de avaliação de professores e alunos constitui-se no primeiro passo rumo à compreensão e superação das dificuldades enfrentadas por ambos ao se depararem com o processo avaliativo.

Os alunos apontam como funções principais da avaliação: medir o aprendizado e aprovar, fazer/ estimular o estudo, avaliar o conhecimento e gerar a nota (Tabela 2).

Tabela 2 - Funções da avaliação apontadas pelos alunos da disciplina de anatomia humana do primeiro ano do curso de odontologia da Universidade Federal de Goiás.

\begin{tabular}{|c|l|}
\hline \% de alunos & \multicolumn{1}{|c|}{ Funções da avaliação em ordem crescente de importância/ } \\
\hline 47,6 & $\begin{array}{l}\text { Medir o aprendizado e aprovar o aluno / Fazer/estimular o aluno a } \\
\text { estudar/Gerar a nota. }\end{array}$ \\
\hline 10 & Avaliar o conhecimento \\
\hline 8,2 & Avaliar o professor \\
\hline 6,5 & Avaliar o grau de aprendizagem ou \\
\hline 6,5 & Testar os conhecimentos \\
\hline 6,6 & Avaliar o aluno \\
\hline 3,3 & Verificar o rendimento \\
\hline 3,3 & Não respondeu \\
\hline 1,6 & Testar o controle e a tranqüilidade do aluno \\
\hline 6,4 & $\begin{array}{l}\text { Reconhecer o interesse do aluno/ Fixar o conhecimento/ Despertar } \\
\text { o interesse pela matéria/ Forçar o comparecimento às aulas }\end{array}$ \\
\hline
\end{tabular}


A maioria dos alunos reduz a avaliação a uma forma de medir conhecimentos, sendo um estímulo para o aluno estudar e assim, gerar um conceito ou nota que identifique aqueles considerados aptos ou não-aptos à aprovação. Para eles, o mais importante é o produto final, ou seja, a nota e não todo o processo de aprendizagem, embora nem sempre as maiores notas correspondam à compreensão verdadeira dos conhecimentos, que expressa a tendência tecnicista na qual se busca a eficiência do produto (RODRIGUES, 1999).

A avaliação também é associada, por alguns alunos $(1,6 \%)$, como uma verdadeira "prova de fogo", tendo como função testar o controle e a tranqüilidade do aluno. Enquanto outros alunos $(3,3 \%)$ não responderam, provavelmente estes ainda não entenderam 0 papel da avaliação no processo de ensino e aprendizagem. Esses resultados reafirmam a concepção tradicional de avaliação da maioria dos alunos observada na questão anterior, e provavelmente é o reflexo de toda uma trajetória escolar, desde o ensino fundamental até o ensino superior, onde a avaliação se apresenta desvinculada da aprendizagem e como um enorme obstáculo a ser ultrapassado para se chegar à aprovação e ao sucesso escolar. Contudo, a avaliação exerce um papel fundamental no processo de ensino-aprendizagem, na medida em que fornece dados sobre o desempenho do aluno, do professor e se está ou não ocorrendo realmente 0 ato de ensinar $e$ aprender (VILLARINHO, 1979).

Outro aspecto relacionado à avaliação como finalidade de medir conhecimentos para gerar a nota, referese ao estímulo a competição e o individualismo entre os alunos, onde cada um "luta" para obter as melhores classificações como se isso fosse garantia certa de aprendizagem. Desta forma, a avaliação reforça, no ensino fundamental médio assim como no superior, o sistema capitalista onde a competição e o individualismo revelam que o sucesso pessoal, profissional, e o conhecimento não são para todos. Para BOURDIEU \& PASSERON (1982) a avaliação assume a função na escola de reproduzir a relação social presentes no capitalismo, bem como sua perpetuação.

A avaliação possui duas funções básicas, o diagnóstico com a capacidade de levantar os problemas, e o prognóstico ao enfrentar os problemas no intuito de solucioná-los DEMO (1999). Assim, a avaliação, quando entendida e utilizada levando em consideração sua riqueza em informações e possibilidade constitui-se numa importante "ferramenta" que auxilia professores e alunos na trajetória do conhecimento.

Os professores participantes desse trabalho citam como funções da avaliação observar o aprendizado, a capacidade do professor em transmitir o conhecimento e como redirecionador do estudo, caso necessário. Observa-se que 
estes resultados são concordantes com

aqueles encontrados na questão anterior, ou seja, os professores entendem o papel da avaliação em avaliar tanto o aluno quanto o professor. CHAVES, (2001) ressalta que o papel da avaliação atua no sentido de fornecer subsídios ao professor para rever o caminho percorrido, buscar novas alternativas, reorientando sua atuação e suas concepções. As mudanças de concepções da avaliação por parte dos professores universitários, constituem-se em um processo lento, árduo, mas necessário. Haja vista, que a avaliação auxilia professores e alunos no caminho que leva a uma aprendizagem significativa e consequentemente na melhor capacitação para o exercício da profissão com qualidade.

\section{CONCLUSÃO}

Constatou-se forte presença da concepção tradicional de avaliação, evidenciada pela maioria dos alunos e professores, com sutil associação da avaliação vinculada á aprendizagem principalmente pelos professores. Houve preferência pela maioria dos alunos e professores em utilizar as provas como principal e melhor instrumento de avaliação. Isto expressa a necessidade de repensar alguns aspectos da avaliação, já que os alunos apontam melhorias no processo avaliativo como recurso para melhor compreensão da disciplina o que contribuirá para a formação e qualificação dos futuros cirurgiões-dentistas. 


\section{REFERÊNCIAS BIBLIOGRÁFICAS}

ALMEIDA, A.M.F.P.M. Avaliação da aprendizagem e seus desdobramentos. Avaliação, v.2, n.2, p.37-50, 1997.

BOCLIN, R. Avaliação de Docentes do Ensino Superior: Um Estudo de Caso. Ensaio: Aval. Pol. Públ. Educ., v.12, no. 45, pp. 959-980, 2004.

BOURDIEU, P \& PASSERON, J. C. A reprodução: Elementos para uma teoria do sistema de ensino. Rio de Janeiro, Editora Plano, 1982.

CHAVES, S. M. A avaliação da aprendizagem no ensino superior. In: MOROSONI, M. (org.). Professor do ensino superior: identidade, docência e formação. Brasília: Editora Plano, 2001.

CUNHA, M. I. O professor universitário na transição de paradigmas. Araraquara: JM Editora, 1998.

DEMO, P. Mitologias da avaliação - de como ignorar, em vez de enfrentar problemas. Campinas, Autores Associados, p.50-56, 1999.

DEPRESBITERIS, L. O desafio da avaliação da aprendizagem - dos fundamentos a uma proposta inovadora. São Paulo, E.P.U., 1989.

HOFFMANN, J. Avaliação: mito e desafio: uma perspectiva construtivista. Porto Alegre: Sagra 1991.

LUCKESI, C.C. Avaliação da aprendizagem escolar: apontamentos sobre a pedagogia do exame. Tec. Educ, v.20, n.101, p.82-86, 1991.

LUCKESI, C.C. Avaliação da aprendizagem escolar. São Paulo: Cortez, 1995.

LUCKESI, C.C. Avaliação Mediadora. Uma prática em construção da pré-escola á universidade. Porto Alegre: Editora Mediação, 1996.

LUCKESI, C.C. Avaliação da aprendizagem escolar. 8a ed. São Paulo, Cortez, 1998. 
LUCKESI, C.C. O que é mesmo o ato de avaliar a aprendizagem? Pátio, v.3, n.12, p.7-11, 2000.

MOREIRA, M. Repensando a avaliação: perspectivas criativas para a educação. Trabalho, Educação e Saúde, v. 4, no. 2, pp. 441-456, 2006.

METZNER, C. Pareceres descritivos de avaliação da aprendizagem: elaboração e ação do professor. In: Igualdade e diversidade na educação. Anais do XI ENDIPE / Encontro Nacional de Didática e Prática de Ensino. Goiânia, 2002.

RODRIGUES, R.R.J.R. Meta-avaliação: o relato de uma experiência na universidade. Avaliação, v.4, n.1, p.51-61, 1999.

ROLDÃO, M. C. Função docente: natureza e construção do conhecimento profissional. Rev. Bras. Educ. vol. 12, no. 34, pp. 94-103, 2007.

VILLARINHO, L.R.G. Didática: Temas selecionados. Rio de Janeiro: Livros técnicos e científicos, 1979.

WACHOWICS, L. A \& ROMANOWSKI, J. P. Avaliação: que realidade é essa? Avaliação, vol.7, no.2, p.81-100, 2002.

ZOCCHE, D. A. A. Educação Profissional em Saúde: Reflexões Sobre a Avaliação. Trabalho, educação e saúde, v. 5 no. 2, pp. 281-295, 2007. 